\title{
Competency Approach to the Formation of Specialists in the Sphere of Economics in Modern Conditions of Globalization
}

\author{
Julia Gnezdova \\ Smolensk State University \\ Smolensk, Russia \\ Iuliy_67@mail.ru
}

\begin{abstract}
The article analyzes the tendencies of integration of Russian education into world educational systems. Today, Russia's accession to the world market of educational services is complicated by a number of factors associated with the high degree of heterogeneity in the economic space for education, the emergence of regional markets and their weak interaction, that by reducing the parameters of the quality of educational services, various prices for educational services, which leads to uneven modern market of educational services The role of Russian education is growing both for the individual and for the society. The article gives an analysis of the concepts of a specialist's competence as "readiness for professional activity in the current economic situation in the immediate future".
\end{abstract}

Keywords-economy; education; professional activity; competence; specialist

\section{INTRODUCTION}

In recent years, due to the progressive development of the domestic economy, a need for practical-oriented economic knowledge has appeared in the country, which is reflected in attracting the attention of education in its applied aspects based on consumer knowledge and entrepreneurial activity. In the current environment of a changing socioeconomic situation, it is important to establish partnerships between the university and stakeholders in the training of personnel that must be in demand today in the labor market. The dynamics of the historical development of education is determined by the processes of preserving traditions, the introduction of innovations, their complementation. Keeping the demand today, these phenomena change their configuration, acquiring various conceptual frameworks. Therefore, competitiveness is closely linked to the philosophy of success and is linked to the responsibility of the specialist for the implementation and consequences of the decisions taken. The competitiveness of a specialist is determined by his professional competence.

\section{OBJECTIVES AND METHODS}

The aim of the work is to generalize the theoretical foundations and systematization of methods of preserving cultural identity and specific features of the education system in Russia, in particular, its continuity and multi-stage and centralized management of educational institutions.

The dynamics of the historical development of Russian education as a whole is determined by the processes of preserving traditions, the introduction of innovations, and their complementation. The demand for education remains the same for today these phenomena change their configuration, acquiring a different conceptual framework. The process of Russia's integration in the world, with its special geopolitical, ethnic and religious position, creates a different system for measuring transformations and actualizing the problems of uniform development of the regions [1].

The purpose of the publication is to analyze the available scientific literature and the results of research on trends in the development of profile education in the Russian Federation and their impact on public policy. The theoretical significance of this work is due to the novelty of the subject and the lack of analogues of the studies carried out. The empirical base used in this scientific work can be used as a material for further in-depth development of the problem of the issue. The materials of the Ministry of Education of the Russian Federation, the Ministry of Regional Development of the Russian Federation, the Ministry of Economic Development, the collective monographs of the author, as well as reports and data from empirical studies of Russian and foreign scientists were used.

\section{RESULTS AND DISCUSSIONS}

\section{A. Analysis of Professional Competence of Specialists in the Sphere of Economy}

Today, the Council of Europe recognized the universal five key competencies: communicative, cognitive, social, intercultural, information. These universal competencies are most productive for the activities of young professionals in different professional communities [2].

A modern approach to learning in the context of modernization of education is the competence approach. Competent approach in education involves the development of skills that allow in the future to act effectively in situations 
of professional, personal and social life. And special importance is given to skills that allow acting in new, problematic situations for which it is impossible to obtain appropriate funds in advance. Skills that help people navigate in new situations of their professional, personal and social life reaching their goals have come to be called competencies or "key competencies." From the point of view of the characteristics of "key competencies", different authors consider this basic question differently.

So the list of key educational competences is determined by A.V. Khutorsky on the basis of the main goals of general education, which are as follows [3]:

- Reflective competence: the willingness to organize their activities in accordance with the positions that I do (I did, I will do?), Why do I do it (I did, I will do?), How do I do it (did, I will do?), What will I get (received) as a result?;

- Technological competence: ability and readiness to understand instructions, description of technology, algorithm of activity, to strict observance of technology of activity;

- Project competence: readiness to analyze the situation, highlight problems, put forward ideas that contribute to solving problems, set goals and correlate them with the aspirations of other people, program and plan their activities, evaluate the results of their activities;

- Communicative competence: readiness to receive the necessary information, to represent and to defend its point of view in a civilized way in a dialogue and in a public speech on the basis of recognition of the diversity of positions and respect for the values of others (religious, ethnic, professional, personal, etc.);

- Information competence: readiness to make reasoned conclusions, carry out information retrieval and retrieve information from various sources on any media, use information to plan and carry out its activities;

- Socio-labor competence: the ability to relate one's aspirations to the interests of other people and social groups, to interact productively with team members who solve a common task.

- We will carry out an analysis of the classification of key competencies, which IAA used in her works. Winter:

- Value semantic competence - meaningful organization of one's own activity. It is a tendency to more clearly understand the values and attitudes towards a specific goal, the tendency to control one's activity, readiness and the ability to learn independently;

- General cultural competence - the use of information from different areas of knowledge, the formation of literate, logically correct speech, the ability to analyze and act from the standpoint of individual areas of human culture, as well as the acceptance of differences, respect for others and the ability to live with people of other cultures, languages and religions;

- Educational and cognitive competence - instilling an interest in learning, the ability to learn throughout life as the basis for continuous learning in the context of both personal professional and social life;

- Information competence - the ability to extract the necessary information using available sources. Possession of these technologies, understanding of their application, weaknesses and strengths and ways to critical judgments regarding information disseminated by mass media and advertising;

- Communicative competence - the ability to work in a group, the ability to work on the result, to prove one's own opinion and to conduct a dialogue, the ability to act in a society taking into account the positions of other people.

Because of the learning process, getting a certain amount of knowledge, learning to acquire knowledge independently, be able to work with information, mastering the ways of cognitive activity, a specialist in the field of economics acquires the following competencies:

1) Educational and cognitive competence. The totality of the competences of the learner in the sphere of independent cognitive activity, which includes elements of logical, methodological, general scientific activity, correlated with the real cognizable objects. This knowledge is the ability to organize goal-setting, analysis, reflection, self-assessment of educational and cognitive activity [1]. The learner learns creative skills of productive activity, methods of actions in non-standard situations, heuristic methods of problem solving. This includes functional literacy: the ability to distinguish facts from conjectures, the possession of measuring skills, the use of probabilistic, statistical and other methods of cognition.

2) Information and communication competence. The reference to examples from life gives the teacher the opportunity to form the information competence of the students. With the help of real objects (TV, tape recorder, telephone, fax, computer, printer, modem, copier) and information technologies (audio and video recording, e-mail, media, Internet), skills are created to independently search, analyze and select the necessary information, organize , convert, save and transmit it [4].

This type of competence is not new in the training system because its implementation involves the use of various collective or communicative techniques of work, such as discussion, group work, pair work, etc. The main thing in the implementation of this competence is the observance of the principle of usefulness of the work.

3) Social and labor competence. This type of competence assumes the mastery of students' knowledge and experience in civil and public activities, in the social 
and labor sphere, in family relations and duties, in matters of economics and law, as well as in professional selfdetermination. That is, this competence implies mastering the students with those subject knowledge, skills and skills that they will use directly in their future life. And assignments can be given a social and labor character, which will introduce the student into a non-standard, but a domestic situation.

4) Value-semantic competence. This is the competence in the sphere of the world view connected with the values of the learner, his ability to see and understand the surrounding world, to orient himself in it, to realize his role and purpose, to be able to choose the target and semantic guidelines for his actions and actions, and make decisions. This competence provides a mechanism for self-determination of the student in situations of educational or other activities [5]. The individual educational trajectory of the learner and the program of his life activity as a whole depend on it.

5) The competence of personal self-perfection. It is aimed at mastering the ways of physical, spiritual and intellectual self-development, emotional self-regulation and self-support. The real object here is the student himself. He takes control of his own interests and opportunities, which is expressed in his continuous self-knowledge, the development of personal qualities necessary for the modern person, the formation of psychological literacy, the culture of thinking and behavior. This competence includes rules of personal hygiene, concern for one's own health, sexual literacy, culture. This includes a set of qualities associated with the basics of safe living [6].

In fact, through the ideology of UNESCO: "education through life". Thus, the competence data correlate with a wide range of human activities, which allows us to consider them as universal. Being the highest (paradigmatic) level of training of a modern specialist, they are embodied in a combination of theoretical, methodological and axiological guidelines for solving scientific and professional problems [7]. The possession of these competencies ensures competitiveness in professional activities.

\section{CONCLUSION}

Today, the future specialist should not limit oneself to a certain amount of knowledge, but learn to independently acquire knowledge, to be able to work with information, to master the cognitive activity methods, so not to lose in future the level of one's competence and constantly strive to improve their A grade diploma of higher education as a "quality product" of the educational system; should be a professionally qualified and educated specialist, have professional competence and readiness for their flexible application [6] [7].

\section{REFERENCES}

[1] V.S. Osipov, T.V. Skryl, V.O. Evseev, An analysis of economic issues of territories of priority development. Research Journal of Applied Sciences. Vol. 11. \# 9. - 2016 - Pp. 833-842.
[2] V.S. Osipov, the Wheel of Competition as a New Instrument of Strategic Management // World Applied Sciences Journal. Vol. 27. \# 8., 2013, pp. 1083-1086.

[3] Lewis, A. Morals, markets and money. London: Pearson, 2002.

[4] H. Haste, Communitarianism and the social construction of morality. Journal of Moral Education, 25(1), 1996, pp. 47-55.

[5] M.E. Kosov, R.G. Akhmadeev, V.S. Osipov, Yu.K. Kharakoz, Smotritskaya I.I. Socio-Economic Planning of the Economy // Indian Journal of Science and Technology. Vol. 9. \# 36., 2016. pp. 102-008.

[6] O.L. Chulanova, The concept of the competence approach in the management of personnel: monograph / O.L. Chulanova, A.Ya. Kibanov, E.A. Mitrofanova, V.G. Konovalova. - M.: SIC INFRA-M, 2014, p. 156.

[7] I. I. Irkhen, Russian education in the field of culture and arts: global and regional dimensions: thesis research : 24.00.01 / Irina Irkhen, Moscow University of Culture and Arts. Moscow, 2012, p. 435. 